\title{
DIVERSITY ANALYSIS OF MOROCCAN CAROB (CERATONIA SILIQUA L.) ACCESSIONS USING PHENOTYPIC TRAITS AND RAPD MARKERS
}

\author{
Ibrahim KONATÉ ${ }^{1}$, Abdelkarim FILALI-MALTOUF $^{1} \&$ El Bekkay BERRAHO ${ }^{*}$ \\ ${ }^{1}$ Mohammed V University- Agdal, Faculty of Sciences, Department of biology, Laboratory of \\ Microbiology and Molecular Biology, Av. Ibn Battouta. PB. 1014. Rabat. Morocco \\ *Corresponding author: berrahobek@yahoo.fr
}

Recibido el 1 de junio de 2007, aceptado para su publicación el 27 de julio de 2007 Publicado "on line" en noviembre de 2007

\begin{abstract}
SUMMARY. Diversity analysis of moroccan carob (Ceratonia siliqua L.) accessions using phenotypic traits and RAPD markers. The carob (Ceratonia siliqua L.) is a perennial leguminous (Caesalpinioideae) that grows as an evergreen shrub or tree. It's an important component of the Mediterranean vegetation and its adaptation in marginal soils of the Mediterranean regions is important environmentally and economically. Phenotypic and genetic diversity among 10 Ceratonia siliqua accessions coming from different areas of Morocco were studied with morphometric and RAPD approaches. The analysis of discriminative fruit characters showed highly significant differences among these accessions, the closely related ones have a similarity level less than $65 \%$. No molecular studies have been carried out so far on Ceratonia siliqua. To provide markers useful for molecular diversity study of the carob tree, genomic DNA extraction and amplification conditions were finalized and 67 arbitrary primers were screened. 52 of them showed clearly reproducible banding patterns. The analysis of RAPD profiles revealed a high degree of genetic diversity within these carob accessions and enabled each of them to be uniquely fingerprinted. Overall, in our study we note that morphological relationship between carob accessions is deeply different to their molecular relationship. Concerning the distribution of the accessions according to their geographical origin, clustering based on RAPD data revealed a rough distribution of theses accessions. Indeed, Sidi Bou Ottman, Demnate and Essaouira accessions coming from the south of Morocco seem to be linked in the PCA plot. However, two geographically distant accessions, Aïn Sfa and Ouazzane coming from the north (about $700 \mathrm{Km}$ ) were clustered with Essaouira and Demanate - Sidi Bou Ottman, respectively.
\end{abstract}

Key words. Carob, Ceratonia siliqua L., genetic variability, morphometry, RAPD.

RÉSUMÉ. Analyse de la diversite des accessions du caroubier marocain (Ceratonia siliqua L.) utilisant des traits phenotypiques et des marqueurs RAPD. Le caroubier (Ceratonia siliqua L.) est une légumineuse pérenne (Caesalpinioideae), à feuillage persistant et pouvant croître entant qu'arbrisseau ou arbre. C'est un composant important de la végétation méditerranéenne et son adaptation aux sols marginaux des régions méditerranéennes est d'une grande importance écologique et économique. La diversité phénotypique et génétique au sein de 10 accessions de caroubier provenant de différentes régions du Maroc a été étudiée par des approches morphométriques et moléculaires (RAPD). L'analyse des caractères morphologiques discriminants du fruit a montré des différences hautement significatives au sein des accessions, puisque les apparentées d'entre elles n'ont approximativement que $65 \%$ de similarité. Jusqu'à nos jours, aucune étude moléculaire n'a été entreprise sur Ceratonia siliqua. Pour mettre à disposition des marqueurs utiles pour l'étude de la diversité moléculaire du caroubier, 
l'extraction de l'ADN génomique et les conditions de l'amplification ont été mises au point et 67 amorces arbitraires ont été criblées. 52 d'entre elles ont montré clairement des profils de bandes reproductibles. L'analyse des profils RAPD a révélé une diversité génétique de haut niveau entre les accessions de caroubier ce qui a permis à chacune d'elles d'être distinguée génétiquement de façon singulière. De manière générale, nous avons noté que la relation morphologique entre les accessions du caroubier est profondément différente de leur relation moléculaire. Concernant la distribution des accessions selon leur origine géographique, le regroupement basé sur les données de la RAPD a révélé une distribution grossière. En effet, les provenances de Sidi Bou Ottman, Demnate et Essaouira, originaires du sud de Maroc, semblent être liés par l'analyse des composantes principales (PCA). Cependant, deux accessions géographiquement distantes, Aïn Sfa et Ouazzane, originaires du Nord (approximativement $700 \mathrm{Kms}$ ) ont été liées avec Essaouira et Demanate - Sidi Bou Ottman, respectivement.

Mots clés. Caroubier, Ceratonia siliqua L., diversité génétique, morphométrie, RAPD.

\section{INTRODUCTION}

The carob (Ceratonia siliqua L.) is a leguminous of the Caesalpinioideae subfamily that grows as a sclerophyllous evergreen shrub or tree up to $15 \mathrm{~m}$ high. It's a dioecious species with some hermaphroditic forms; thus male, female and hermaphrodite flowers are generally borne on different trees (Tucker, 1992a). The carob tree is an important component of the Mediterranean vegetation and its cultivation in marginal and prevailing calcareous soils of the Mediterranean region is important environmentally and economically. Traditionally, carob trees have been interplanted with olives, grapes, almonds and barley in low-intensity farming systems in most producing countries. Carob pods with their sugary pulp are a staple in the diet of farm animals and are eaten by children as snacks or by people in times of famine. However, currently the main interest is seed production for gum extraction (Batlle. \& Tous, 1997). World production is estimated to about $310000 \mathrm{t} /$ year with very variable yields depending on cultivar, region and farming practice. Spain is the leading carob producer with an average of $135000 \mathrm{t}$ /year, followed by Italy, Portugal, Morocco, Greece, Cyprus, Turkey, Algeria and some other countries (Tous et al. 1992).

In Morocco, the carob tree is present as spontaneous or artificial populations on the large part of the country, even in the arid zones. During the last fifty years, human populations have increased and the concomitant expansion of livestock ranges and the massive use of the fire wood have led to deforestation of wide arid and semiarid areas of Morocco. An efficient agroforestry program to recover these areas may take advantage of multipurpose plant species that are able to grow in inappropriate soils. Among these species, carob tree tolerate extreme dryness and adapt well to degraded soils, and it play an important role in the conservation and improvement of soil fertility. Some new orchards have recently been planted and Moroccan Carob production estimated to be about $50000 \mathrm{t}$ (Gharnit et al. 2001) is expected to rise moderately in the coming years.

Although, we are more and more interested in this plant in many programs of reforestation through the Mediterranean basin, the carob tree, compared to other Mediterranean fruit species, has been neglected with respect to both cultural practices and research. It was the subject of some scientific studies like in vitro culture (Belaizi et al.,1994; Konaté, 2001), 
resistance to the water stress (Rajeb,1992), morphological and social characterization (Guarnit et al., 2001) and enzymatic studies (Tous et al., 1992). However, no molecular studies have been carried out so far on this tree.

Morphological characters and random amplified polymorphic DNA (RAPD) analysis are broadly used in plant population diversity (Crouch et al. 2000, Casiva et al. 2002; Garcia et al. 2002; Samal et al. 2003). Mainly, RAPD has allowed the resolution of complex taxonomic relationships. Likewise, morphological characters constitute basic information for plant systematic. Therefore, in the present study we used morphological traits of the siliqua and RAPD approaches to characterize Moroccan accessions of Ceratonia siliqua so that we could evaluate their phenetic relationships.

\section{MATERIALS AND METHODS}

\section{Plant material}

Ten natural populations ofCeratonia siliqua distributed in different regions of Morocco (fig. 1) were collected for this study. Each natural population was sampled as a bulk of mature pods randomly collected from at least ten trees that were separated from each other by more than $40-50 \mathrm{~m}$. The set of pods collected of a every region is considered as an accession.

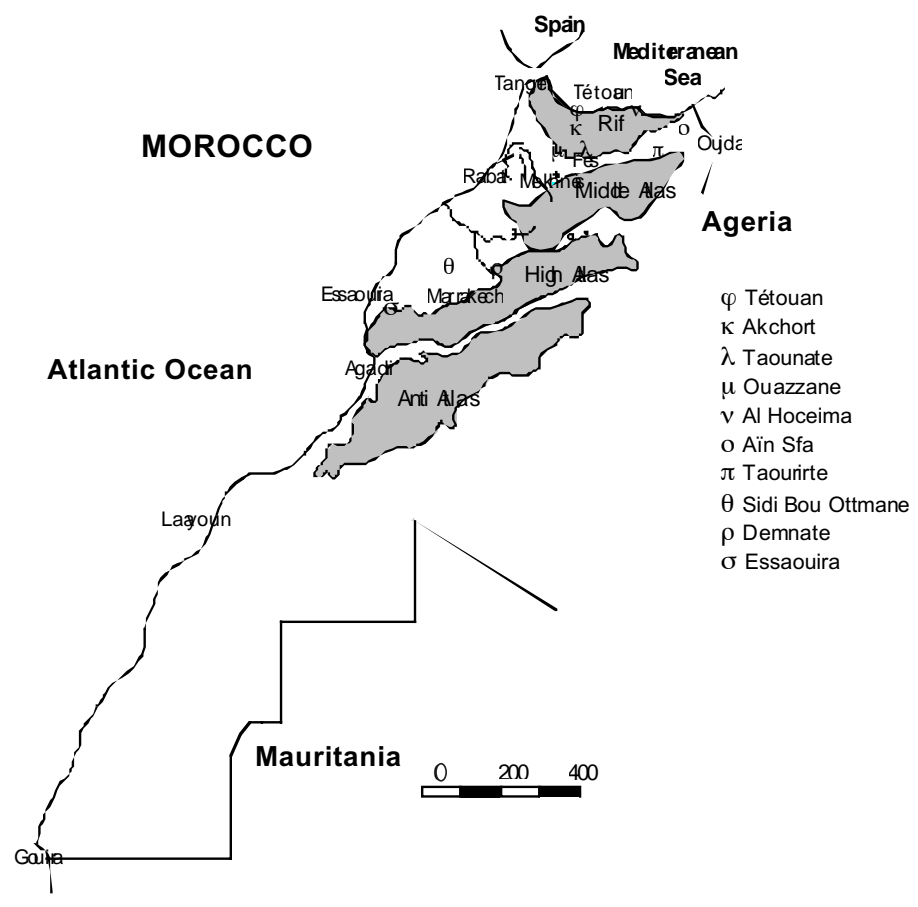

Figure 1. Map of Morocco: Geographical distribution of carob populations from which fruits were collected 


\section{Morphometric methods}

One hundred pods taken randomly of each accession were used to measure quantitative trait variation within and among populations. Ten discriminative characters of the siliqua: length, width, thickness, rope, weight, number of seeds/pod, weight of seeds, number of aborted seeds, pulp weight and the output in seeds of every pod, were recorded.

\section{RAPD methods}

\section{Extraction of genomic DNA}

According to Konate (2001), the carob accessions coming from different regions of Morocco, showed a notable variability even at the level of the seed tegument hardness. To have a good germination rate, scarification of seeds coming from different accessions required a variable length of soaking in the sulphuric acid. Therefore, in our study, seeds were scarified by concentrated sulphuric acid (95\%) for 30 to 45 min depending on the provenance of the accession. After washing and imbibing them in sterile water for $24 \mathrm{~h}$, seeds were placed on moistened Watman paper in Petri disk. After germination, seedlings were transferred in pots containing a fertile soil and are placed in a growth chamber. Six months later, leaves are harvested and stocked in freezer at $-80^{\circ} \mathrm{C}$.

For each accession, leaves of 50 plants have been mixed for the DNA bulk extraction using a modification of the method of Ouenzar et al. (1998). 1g of cool leaves were cut finely then ground in $5 \mathrm{ml}$ of the lysis buffer: $50 \mathrm{mM}$ Tris- $\mathrm{HCl}$ (pH8), 5 mM EDTA (pH8), $300 \mathrm{mM}$ mannitol, 0.05\% BSA, 1\% PEG 600 and $0.5 \%$ b-mercaptoethanol. The suspension was transferred in tubes containing $600 \mu \mathrm{l}$ of SDS $(20 \%)$ and $400 \mu \mathrm{l}$ of sodium acetate $(3 \mathrm{M}, \mathrm{pH} 8)$ then incubated at $65^{\circ} \mathrm{C}$ for $30 \mathrm{~min}$. The mixture was washed three times successively: the first and the third washing with chloroform-isoamyl alcohol (24/1) and the second with the phenol/chloroform/isoamyl alcohol (25/24/ 1). Every washing was followed by a centrifugation at $10000 \mathrm{x}$ g for $10 \mathrm{~min}$. The last aqueous supernatant was recovered in fresh tubes and an equal volume (v/v) of cold isopropanol was added before keeping the tubes at $-20^{\circ} \mathrm{C}$. One hour later, the suspension was centrifuged at $10000 \mathrm{xg}$ for $20 \mathrm{~min}$, the pellet was twice washed with cold ethanol (70\%), airdried and redisolved in TE buffer (10 mM Tris, $1 \mathrm{mM}$ EDTA, $\mathrm{pH}$ 7.4) then treated with $\mathrm{K}$ proteinase $(20 \mu \mathrm{g} /$ $\mathrm{ml}$ ) and incubated at $37^{\circ} \mathrm{C}$ for $30 \mathrm{mn}$. The $\mathrm{K}$ proteinase was removed by one extraction with phenol/chloroform/isoamyl alcohol. After centrifugation, $10 \mu$ the superior phase with an equal volume (v/v) of absolute cold ethanol were added with $1 \mu \mathrm{l}$ of $\mathrm{NaCl}(5 \mathrm{M})$ then incubated over night at $-20^{\circ} \mathrm{C}$. The DNA was pelleted by centrifugation at $10000 \mathrm{x} \mathrm{g}$ for $20 \mathrm{~min}$ and after washing with cold ethanol, the pellet was airdried and dissolved in $200 \mu \mathrm{L}$ of TE buffer then digested with 2 $\mu \mathrm{L}$ of RNAase $(10 \mu \mathrm{g} / \mathrm{ml})$ and incubated at $37^{\circ} \mathrm{C}$ for $30 \mathrm{~min}$. The DNA concentration was determined by using spectrophotometer at $260 \mathrm{~nm}\left(1 \mathrm{OD}_{260}=50 \mathrm{ng} / \mu \mathrm{L}\right)$.

\section{PCR-RAPD amplification}

The polymerase chain reaction (PCR) conditions were finalized by varying the hybridization temperature (Tm), the concentration of $\mathrm{MgCl}_{2}$, the units of Taq polymerase and the quantity of DNA template. 67 decanucleotidic arbitrary primers (Operon, USA) were screened in a small number of accessions. 52 of them were chosen because they showed clearly reproducible banding patterns. The PCR was carried out in $25 \mu \mathrm{L}$ final volume containing $2.5 \mathrm{mM} \mathrm{MgCl}_{2}, 25 \mathrm{mM} \mathrm{dNTP}, 10 \mu \mathrm{M}$ primers, 16 ng template DNA and 1.5 units of Taq polymerase (Promega). The 


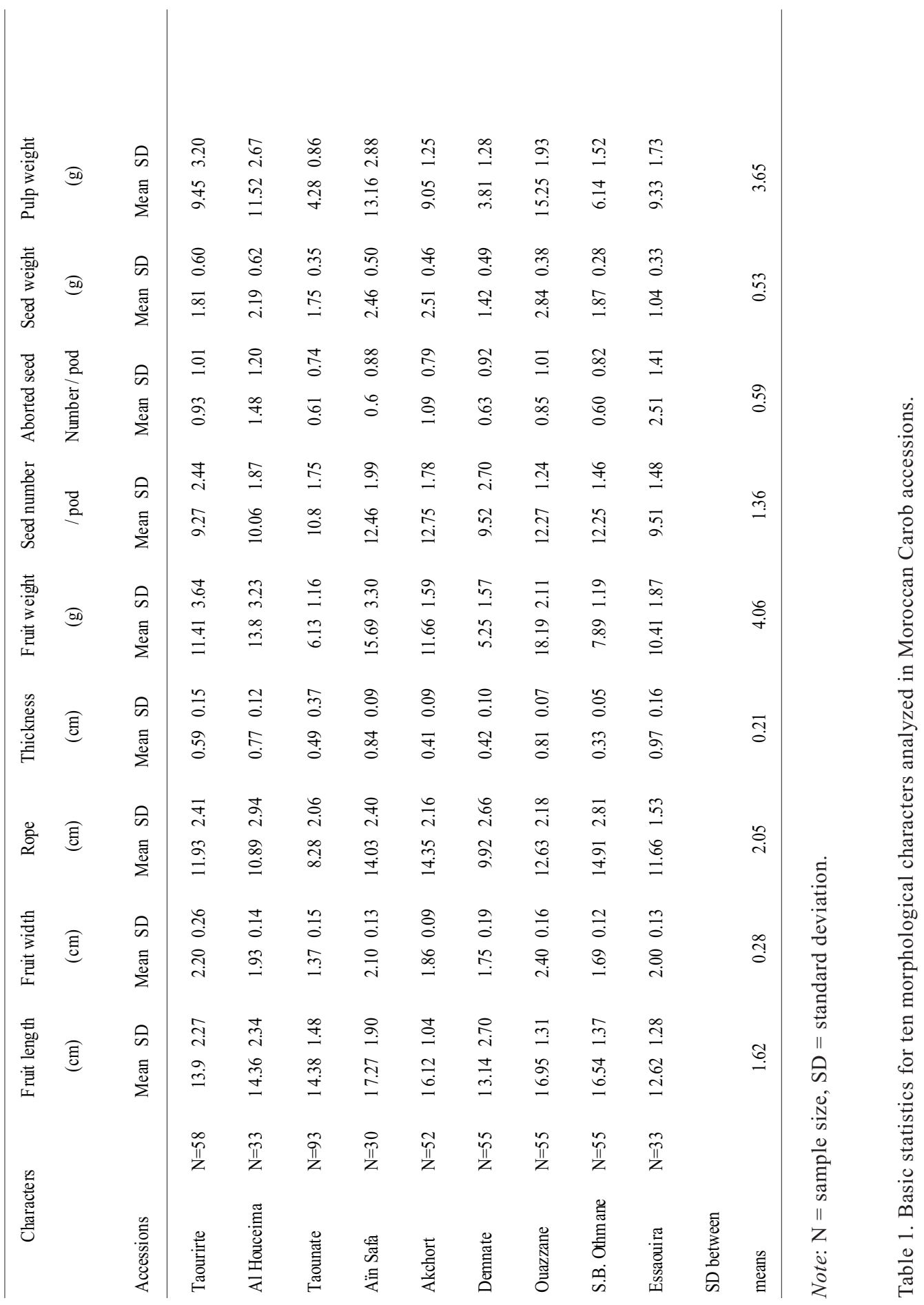


amplification was performed in a thermocycler AMPLITRON-RII according to the following program: 1 cycle of $94^{\circ} \mathrm{C}$ for $4 \mathrm{~min}, 45$ cycles of $92^{\circ} \mathrm{C}$ for $1 \mathrm{~min}, 33^{\circ} \mathrm{C}$ for $1 \mathrm{~min}$, and $72^{\circ} \mathrm{C}$ for $2 \mathrm{~min}$. A final extension step at $72^{\circ} \mathrm{C}$ for 10 min was performed to ensure complete extension.

At the end of the polymerase chain reaction (PCR), amplification products were separated by electrophoresis in $1.2 \%$ agarose gels. It was performed in $1 \mathrm{XTBE}$ (trisborate-EDTA) running buffer at 60 volts for $4 \mathrm{~h}$ and then the revelation of RAPD profiles was done by ethidium bromide staining under ultra-violet light. Molecular weights were estimated using 100 bp PCR markers from Promega.

\section{Data analysis}

Using the program STATISTICA, phenetic relationships among populations were evaluated by cluster analysis from the matrix of average values of morphometric traits. Each accession was considered as an operational taxonomic unit. The relationships among the accessions were estimated by the Pearson coefficient (r). Distance values $(D)$ were defined as follows: $D=1-r$, and the distance matrix was represented in a phenogram by the UPGMA clustering method (Sneath \& Sokal, 1973). To identify those morphological characters that were most important in the differentiation of accessions, we conducted the principal component analysis (CPA) with the STATISTICA program.

For the RAPD markers, only reproducible and well-defined bands in each of the three replications were considered as potential polymorphic markers and were scored as 1 (present) or 0 (absent) in a binary matrix for each primer. Similarities between accessions were evaluated by Pearson correlation coefficient and the accessions were grouped by the UPGMA clustering method using the STATISTICA program. With the same program, relationships between carob accessions were also evaluated by the CPA analysis.

\section{RESULTS AND DISCUSSION}

Morphometric analysis: The choice of fruit to assess carob diversity is not fortuitous. It emanates because several authors had resort to the use of these pods, to identify, to label or to characterize different carob collections or germaplasms (Marakis et al. 1988; Tous et al. 1996; Batlle \& Tous, 1997; Gharnit et al. 2001).

The means of morphometric characters measured in the studied Moroccan carob accessions were compared (tab. 1). The results showed highly significant differences among the accessions for all the examined characters, especially for Weight fruit. Similarities among accessions were evaluated with the Pearson correlation coefficient (r), and distances values were represented in a UPGMA phenogram (fig.2). This figure showed that, below the boundary level 0.5 of correlation coefficient, the accessions were divided into five clusters. Four clusters, containing two accessions in each one: Taourirt - Al Hoceima, Aïn Sfa Ouazzane, Toaunate - Demnate and Akchort - Sidi Bou Ottmane and the fifth contains only one accession from Essaouira. This latter accession (Essaouira) is distant of the others, mainly under the effect of the raised number of aborted seeds.

The principal component analysis (CPA) that reduces the dimensions of data by eliminating redundancies caused by correlations among variables, identified out of the initial nine variables three principal components (PC) that explained more than $73.5 \%$ of the total variance. The PCA plot shows the relationship among the studied 


\begin{tabular}{|c|c|c|c|c|c|}
\hline primer & $\begin{array}{l}\text { Sequence of primer } \\
\left(5^{\prime}-3^{\prime}\right)\end{array}$ & $\begin{array}{l}\text { Amplified } \\
\text { products }\end{array}$ & primer & $\begin{array}{l}\text { Sequence of primer } \\
\left(5^{\prime}-3^{\prime}\right)\end{array}$ & $\begin{array}{c}\text { Amplified } \\
\text { products }\end{array}$ \\
\hline $\mathrm{OPB}_{10}$ & 5'-CTGCTGGGAC-3' & 10 & $\mathrm{OPG}_{5}$ & 5'-CTGAGACGGA-3' & 5 \\
\hline $\mathrm{OPC}_{1}$ & 5'-TTCGAGCC AG-3' & 18 & $\mathrm{OPH}_{2}$ & 5'-TCGGACGTGA-3' & 1 \\
\hline $\mathrm{OPC}_{2}$ & 5'-GTGAGGCGTC-3' & 1 & $\mathrm{OPH}_{3}$ & 5'-AGACGTCCAC-3' & 8 \\
\hline $\mathrm{OPC}_{3}$ & 5'-GGGGGTCTTT-3' & 14 & $\mathrm{OPH}_{4}$ & 5'-GGAAGTCGCC-3' & 11 \\
\hline $\mathrm{OPC}_{4}$ & 5'-CCGCATCTAC-3' & 17 & $\mathrm{OPH}_{5}$ & 5'-AGTCGTCCCC-3' & 13 \\
\hline $\mathrm{OPC}_{5}$ & 5'-GATGACCGCC-3' & 8 & $\mathrm{OPI}_{2}$ & 5'-GGAGGAGAGG-3' & 6 \\
\hline $\mathrm{OPC}_{6}$ & 5'-GAACGGACTC-3' & 7 & $\mathrm{OPI}_{3}$ & 5'-CAGAAGCCCA-3' & 10 \\
\hline $\mathrm{OPC}_{7}$ & 5'-GTCCCGACGA-3' & 4 & $\mathrm{OPI}_{4}$ & 5'-CCGCCTAGTC-3' & 3 \\
\hline $\mathrm{OPD}_{1}$ & 5'-ACCGCGAAGG-3' & 15 & $\mathrm{OPM}_{1}$ & 5'-TCTGTTCCCC-3' & 1 \\
\hline $\mathrm{OPD}_{2}$ & 5'-GT CGCCGTCA-3' & 9 & $\mathrm{OPR}_{1}$ & 5'-TGCGGGTCCT-3' & 11 \\
\hline $\mathrm{OPD}_{3}$ & 5'-GT CGCCGTCA-3' & 11 & $\mathrm{OPR}_{2}$ & 5'-TGAGCACGAG-3' & 2 \\
\hline $\mathrm{OPD}_{4}$ & 5'-TCTGGTGAGG-3' & 7 & $\mathrm{OPR}_{11}$ & 5'-GTAGCCGTCT-3' & 2 \\
\hline $\mathrm{OPD}_{5}$ & 5'-TGAGCGGACA-3' & 5 & $\mathrm{OPS}_{3}$ & 5'-TTTGGGGCCT-3' & 2 \\
\hline $\mathrm{OPD}_{15}$ & 5'-CATCCGTGCT-3' & 5 & $\mathrm{OPS}_{4}$ & 5'-TCCTGGTCCC-3' & 4 \\
\hline $\mathrm{OPD}_{20}$ & 5'-ACCCGGTCAC-3' & 1 & $\mathrm{OPS}_{5}$ & 5'-ACCGTTCCAG-3' & 2 \\
\hline $\mathrm{OPE}_{1}$ & 5'-CCCAAGGTCC-3' & 10 & $\mathrm{OPS}_{6}$ & 5'-AAAGGGGTCC-3' & 1 \\
\hline $\mathrm{OPE}_{2}$ & 5'-GGTGCGGGAA-3' & 7 & $\mathrm{OPS}_{7}$ & 5'-GAGTCACCAG-3' & 1 \\
\hline $\mathrm{OPE}_{3}$ & 5'-CCAGATGCAC-3' & 12 & $\mathrm{OPS}_{8}$ & 5'-TCTGGACGCT-3' & 5 \\
\hline $\mathrm{OPE}_{4}$ & 5'-GTGACATGCC-3' & 8 & $\mathrm{OPS}_{18}$ & 5'-CTGGCGAACT-3' & 2 \\
\hline $\mathrm{OPF}_{1}$ & 5'-ACGGATCCTG-3' & 10 & $\mathrm{OPT}_{1}$ & 5'-GGGCCACTCA-3' & 10 \\
\hline $\mathrm{OPF}_{2}$ & 5'-GAGGATCCCT-3' & 3 & $\mathrm{OPT}_{4}$ & 5'-GGGTTTGGCA-3' & 11 \\
\hline $\mathrm{OPF}_{3}$ & 5'-CCTGATCACC-3' & 6 & $\mathrm{OPT}_{5}$ & 5'-AACGGCGACA-3' & 7 \\
\hline $\mathrm{OPF}_{4}$ & 5'-GGTGATC AGG-3' & 5 & $\mathrm{OPT}_{6}$ & 5'-AGGACTGCCA-3' & 15 \\
\hline $\mathrm{OPF}_{5}$ & 5'-CCGAATTCCC-3' & 7 & $\mathrm{OPT}_{16}$ & 5'-GGTGAACGCT-3' & 7 \\
\hline $\mathrm{OPG}_{2}$ & 5'-GGCACTGAGG-3' & 10 & $\mathrm{OPU}_{3}$ & 5'-CTATGCCGAC-3' & 2 \\
\hline $\mathrm{OPG}_{3}$ & 5'-GAGCCC TCCA-3' & 11 & $\mathrm{OPY}_{15}$ & 5'-AGTCGCCCTT-3' & 11 \\
\hline
\end{tabular}

Table 2: Selected Oligonucleotide primers with the number of amplified products. 


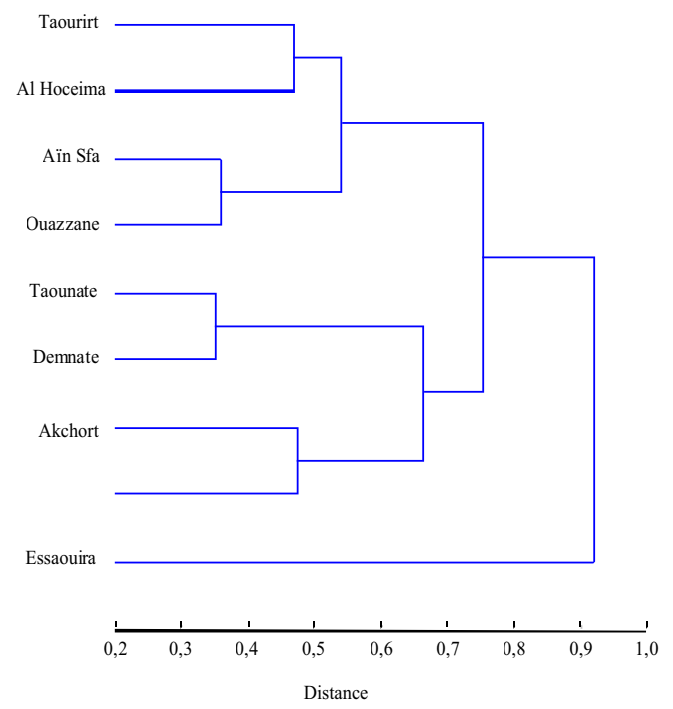

Figure 2. UPGMA phenogram highlighting the morphometric similarities among Moroccan carob accessions. Similarities among accessions were evaluated with Pearson coefficient.

accessions (fig.3). The most important characters for accession differentiation were fruit width and seed weight, they had high loadings on all three principal components. Principal component 1 , witch is accounted for $38.7 \%$ of total variance, discriminates five accessions: Taourirt, Al Hoceima, Aïn Sfa, Akchort and Sidi Bou Ottmane. Principal component 2 explaining $20.2 \%$ of total variance reveals the relatedness between Taounate and Demnate accessions. Principal component 3, accounted for only $14.6 \%$ of total variance, reflects a negative correlation between Ouazzane and Essaouira accessions.

Random amplified polymorphic DNA analysis: Although the leaves of the carob tree are hard and tough, we have finalized a protocol adapted for the extraction of genomic DNA. Amplification was successful with all 67 screened arbitrary primers, but only 52 of them generated polymorphic and reproducible bands in the four accession

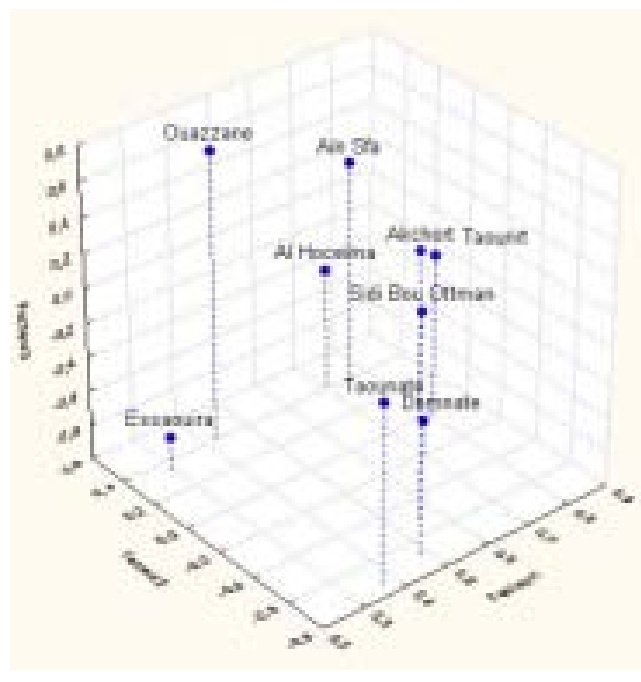

Fig.3. Principal components analysis (PCA) plot from morphomertic data, showing the distribution of Moroccan carob accessions.

screening set (tab. 2). These 52 primers were then used to screen all accessions. They yielded a total of 374 bands with an average of 7.2 bands / primer. The number of polymorphic fragments per primer was ranger from one $\left(\mathrm{OPC}_{2}\right)$ to $18\left(\mathrm{OPC}_{1}\right)$ and fragment size ranged from $40 \mathrm{bp}\left(\mathrm{OPD}_{5}\right)$ to $2000 \mathrm{bp}\left(\mathrm{OPS}_{18}\right)$. The amplification product obtained by primers $\mathrm{OPE}_{3}$ and $\mathrm{OPG}_{2}$ were illustrated in figure 4 which exemplifies typical RAPD banding patterns observed.

From the Pearson correlation coefficient Matrix (tab. 3), a UPGMA phenogram was constructed (fig. 5). The cluster analysis indicates that the accessions of Carob were grouped roughly into two highly distant groups, one minor group having only tow accessions Taounate and Tetouan and one major group containing all the other accessions. However, when we take into account the values of aggregation distance, we note that all accessions are highly distant, since the two accessions forming the minor 


\begin{tabular}{|c|c|c|c|c|c|c|c|c|c|}
\hline Taourirt & $\begin{array}{c}\text { Al } \\
\text { Hoceima }\end{array}$ & Taounate & Aïn Sfa & Akchort & Demnate & Ouazzane & $\begin{array}{c}\text { Sidi Bou } \\
\text { Ottman }\end{array}$ & Essaouira & Tetouan \\
\hline \multicolumn{10}{|l|}{0,00} \\
\hline 0,91 & 0,00 & & & & & & & & \\
\hline 0,97 & 1,01 & 0,00 & & & & & & & \\
\hline 0,78 & 0,93 & 1,01 & 0,00 & & & & & & \\
\hline 0,92 & 0,92 & 0,93 & 0,86 & 0,00 & & & & & \\
\hline 0,95 & 1,02 & 1,07 & 0,86 & 0,96 & 0,00 & & & & \\
\hline 0,82 & 0,98 & 1,08 & 0,86 & 0,82 & 0,73 & 0,00 & & & \\
\hline 0,95 & 0,90 & 1,01 & 0,87 & 0,80 & 0,70 & 0,80 & 0,00 & & \\
\hline 0,88 & 0,86 & 0,93 & 0,77 & 0,89 & 0,88 & 0,81 & 0,70 & 0,00 & \\
\hline 1,02 & 1,08 & 0,94 & 1,00 & 0,91 & 0,92 & 1,02 & 0,89 & 0,93 & 0,00 \\
\hline
\end{tabular}

Table 3. Pearson correlation coefficient Matrix evaluated from RAPD data.

group have only $6 \%$ of similarity between them and the two nearest accessions, Demnate and sidi Bou Ottmane, were only correlated to a level of $30 \%$. This remoteness between the accessions is also reflected by the results of the PCA. Indeed, the principal component analysis identified out three principal components that explained only $43.77 \%$ of the total variance. As shown in the previous dendrogram, the PCA plot reflects also a weak genetic relationship among the studied accessions (fig. 6). This low relationship is remarkable even within the accessions coming from the same geographical area.

Comparison of phenotypic and molecular analysis: A comparison of molecular and phenotypic data was made on the basis of Pearson similarity coefficient. Results obtained from dendrogram based on similarity coefficients of morphological characters were grouped into five clusters with 50\% similarity. However, a dendrogram obtained by RAPD analysis revealed large differences between the clusters. Indeed, when we take into account the values of genetic distance, we note that all accessions are highly distant. For example, the nearest accessions Aï Sfa and Ouazzane showing $65 \%$ similarity in morphology were found to be only about $18 \%$ similar at a molecular level. Overall, in our study we note that morphological relationship between carob accessions is deeply different to their molecular relationship. This observation was reported in varieties of cashew (Anacardium occidentale L.) that have similar morphological characters but can be largely different from each other at the genotypic level (Samal et al., 2003). The discrepancies between RAPD data and morphologically based groupings were reported also in 


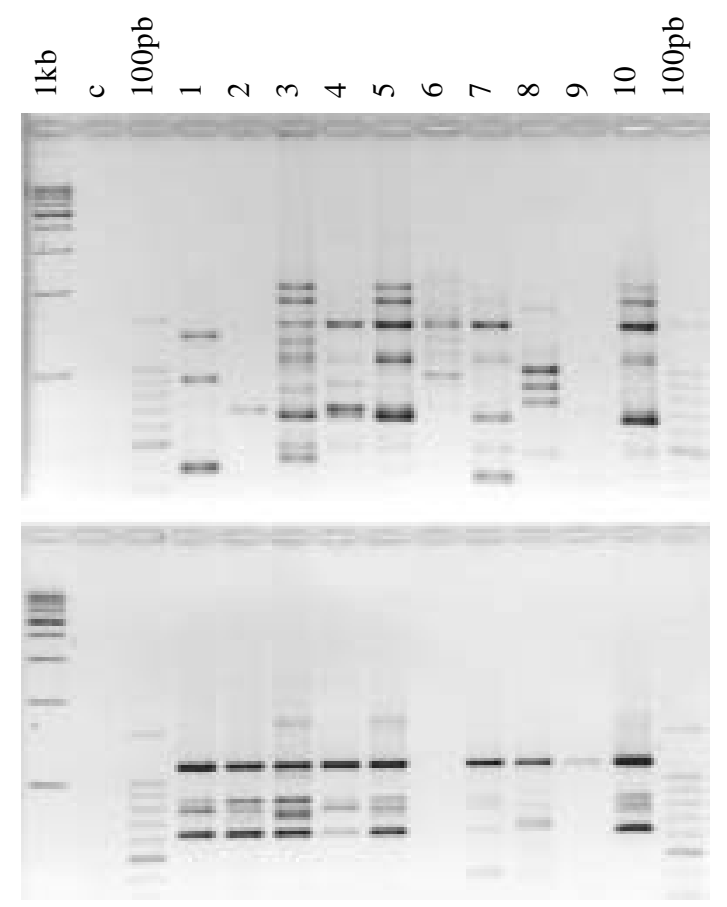

Figure 4. Example of amplification products from primers OPE3 (A) and OPG2 (B). C: control, 1: Taourirt, 2: Al Houceima, 3: Taounate, 4: Aïn Sfa, 5: Akchrt, 6: Demnate, 7: Ouezzane, 8: Sidi Bou Othmane, 9: Essaouira, 10: Tétouan.

Fragaria sp (Harrison et al. 1997); in Hordeum vulgare (Papa et al. 1998) and in Rhenum spp. (Persson et al. 2000). Smith \& smith (1989) suggested that the use of morphological traits is not always the best way to evaluate genetic distance since the degree of divergence between genotypes at the phenotypic level is not necessary correlated with a similar degree of genetic difference. According to these authors, molecular markers provide a better coverage of the genome, resulting in a better estimation of relationships. Otherwise, most of morphological traits measured in our study to evaluate the polymorphism among carob accession, could be influenced by climatic conditions. Bean size, numbers of aborted seeds and bean and seed weight were reported to be variable from year to year and according to climatic conditions (Garbagallo et al.1997). Therefore, these last authors, as well as Bachmann (1992) stated that differences in phenotypic characters are not necessarily reflections of different genetic events, even though it may sometimes be useful for making a crude classification of different plant accessions.

Concerning the distribution of our carob accession according to their geographical origin, the dendrogram and the PCA established from morphometric data, showed a promiscuity of accessions and no correlation between their clustering and their geographical origin was shown. By contrast, Clustering based on RAPD data revealed a rough distribution of accessions according to their geographical origin. Indeed, Sidi Bou Ottman, Demnate and Essaouira accessions 


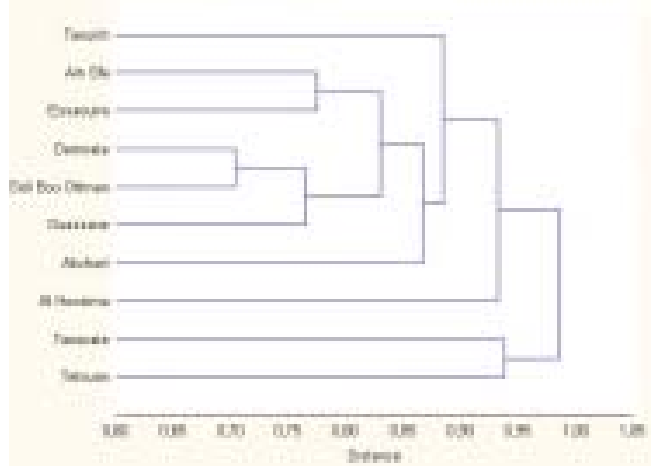

Figure 5. Dendrogram generated with all (374) random amplied polymorphic DNA characters using Pearson coefficient

coming from the south of Morocco seem to be linked in the PCA plot. However, two geographically distant accessions, Aïn Sfa and Ouazzane coming from the north (about $700 \mathrm{Km}$ ) were clustered with Essaouira and Demanate - Sidi Bou Ottman, respectively.

This first genetic diversity analysis of Moroccan carob populations has led to useful information which could help to preserve the genetic diversity of the species and to identify some Moroccan cultivars. Until now, no Moroccan cultivar is identified nor listed in the forest catalogue. The quasi-totality of the carob-tree plantations is of wild type and the few new orchards result from the grafting of the wild carob-tree by an another wild individual selected on the basis of the quality of its fruits. This molecular characterization could be exploited therefore to label some accessions and so to identify the first Moroccan cultivars.

ACKNOWLEDGEMENTS. This work was supported by research grants from the Moroccan Ministry of Higher Education (Potars I project) and from IRD (Aire development project: 01-2MAR-28-1). The authors are grateful to Dr.

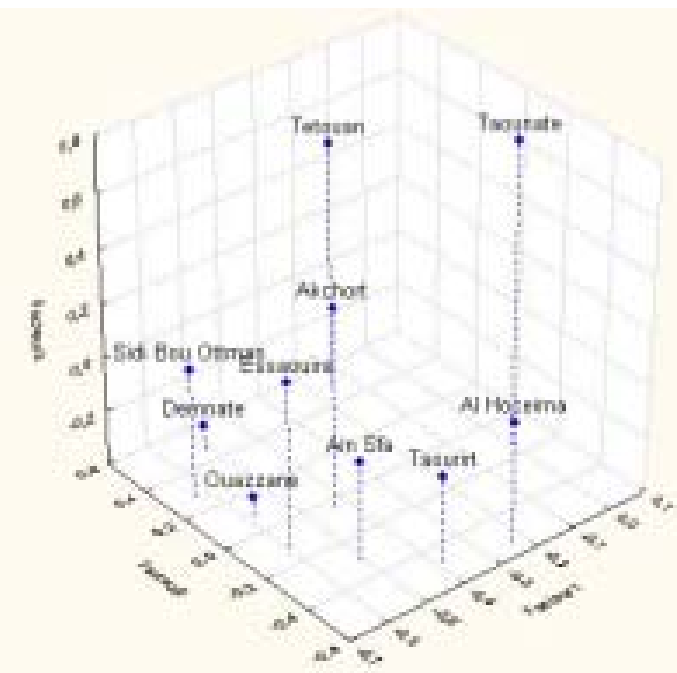

Figure 6. Principal components analysis (PCA) plot from RAPD data showing the distribution of the Moroccan carob accessions.

Mohammed ABOUROUH, Dr. Hassan SBAI and Pr Ahmed LAMARTI for their help during the collection of the plant material.

\section{REFERENCES}

BACHMANN K. -1992- Phenotypic similarities and genetic relationship of populations of Microseris bigelovi (Asteraceae: Lactuceae). Bot. Acta 105: 337-342.

BATLLE, I. \& J. TOUS -1997- Carob tree. Ceratonia siliqua L. Promoting the conservation and use of underutilized and neglected crops. 17. Institute of Plant Genetics and Crop Plant Research, Gatersleben/International Plant Genetic Resources Institute, Rome, Italy.

BELAIZI M., M. R. BLEN \& P. BOXUS -1994 Régénération in vitro et acclimatation du caroubier (Ceratonia siliqua L.). Dans: Quel avenir pour l'amélioration des plantes? Ed. AUPELF-UREF. J. L. Eurotext. Paris. 1994; p: $227-232$.

CASIVA P.V., B. O. SAIDMAN, J. C. VILARDI, \& A.M. CIALDELLA-2002- First comparative phonetic studies of Argentinean species of 
Acacia (Fabaceae), using morphometric, isozymal and RAPD approaches. American Journal of Botany 89(5): 843-853.

CROUCH H.K, J.H. CROUCH, S. MADSEN, D.R. VUYLSTEKE \& R. ORTIZ -2000Comparative analysis of phenotypic and genotypic diversity among plantain landraces (Musa spp., AAB group). Theor. Appl. Genet 101:1056-1065.

GARBGALLO M.G., R. DI LORENZO, R. MELI \& G. CRESCIMANNO-1997- Characterization of carob germaplasm (Ceratonia siliqua L.) in Sicily. J. Hort. Sc, 72 (4): 537-543.

GARCIA M. G., M. ONTIVERO, J. C. DIAZ RICCI \& A. CASTAGNARO -2002Morphological traits and high resolution RAPD markers for the identification of the main strawberry varieties cultivated in Argentina. Plant Breeding 121, 76-80.

GUARNIT N., E. M. NOUREDDINE, T. E. AHMED \& E. ABDESLAM -2001- Social characterization and exploitation of carob tree (Ceratonia siliqua L.) from Mokrisset and Bab Taza (NW of Morocco). Sci. letters, vol. 3, No. 2, July 2001. QARTICLE

HARRISON L.F., J.J. LUBY, G.R. FOURNIER \& H. HANCORK -1997- Morphological and molecular variation among populations of octaploid Fragaria virginiana and F. chloronum (Rosaceae) from North America. Am. J. Bot. 84: 612-620.

KONATÉ I. -2001- Amélioration de la culture du caroubier (Ceratonia siliqua L.) via la multiplication in vitro et la fixation symbiotique de l'azote. Mémoire du DESA. Univ. Ibn Tofaïl, Fac. Sci. Kenitra. 58p.

MARAKIS, S., J. KALAITZAKIS \& K. MITRAKOS. -1988-Criteria for recognizing carob tree varieties. Pp. 558-566 in Proceedings of the II International Carob Symposium (P. Fito and A. Mulet, eds.). Valencia, Spain.

OUENZAR B., C. HARTMAN, A. RODE \& A. BENSLIMANE -1998- Data Palm DNA Minpreparation without liquid Nitrogen. Plant Molecular Biology Reporter. 16: 263-269.
PAPA R., G. ATTENE, G. BARCACCIA, A OHGATA \& T. KONISHI -1998-Genetic diversity in landrace populations of Hordeum vulgare L. from Sardinia, Italy, as revealed by RAPDs, isozymes and morphological traits. Plant breeding 117: 523-530.

PERSSON H.A., K. RUMPUNEN \& L.K. MOLLERSTEDT -2000- Identification of culinary rhuarb ( Rheum spp.) cultivars using morphological characterization and RAPD markers. J. Hort. Sci. Biotechnol. 75: 684689.

RAJEB N. M. -1992- Etude des mécanismes de résistance à la sécheresse du caroubier (Ceratonia siliqua L.) en Tunisie. Thèse de Doc. d'Etat es-Sci. de Tunis; 199p.

SAMAL S., G.R. ROUT \& P.C. LENKAET 2003-Analysis of genetic relationships between populations of cashew (Anacardium occidentale L.) by using morphological characterisation and RAPD markers. Plant Soil Environ. 49, (4): 176-182.

SMITH J.S.C. \& O.S. SMITH -1989- The description and assessment of distances between inbred lines of maize. II. The utility of morphological, biochemical and genetic descriptors and a scheme for the testing of distinctiveness between inbred lines. Maydica 34: 151-161

SNEATH, P. H. A., \& R. R. SOKAL -1973Numerical taxonomy: the principles and practice of numerical classification. W. H. Freeman, San Francisco, California, USA.

TOUS J., C. OLARTE, M. J. TRUCO \& P. ARÙS -1992- Isozyme polymorphisms in carob cultivars. Hort. Sci., vol. 27 (3): 257-258.

TOUS J., ROMERO A., PLANA J. \& BATLLE I. -1996-Current situation of carob plant material. In Proceedings of the III International Carob Symposium. CabanasTavira. Portugal.

TUCKER, S.C. -1992a- The developmental basis for sexual expression in Ceratonia siliqua (Leguminosae: Caesalpinioideae: Cassieae). Am. J. Bot. 79(3):318-327. 